\title{
Evaluation of Resistivity Anisotropy of Parts of Ijebu Igbo, Southwestern, Nigeria Using Azimuthal Resistivity Survey (ARS) Method
}

\author{
Bayewu, Olateju O. ${ }^{1}$, Oloruntola Moroof O. ${ }^{2}$, Mosuro Ganiyu O. ${ }^{1}$, Folorunso, Ismail O. ${ }^{3}$ \& Kolawole, Ajibola. \\ $\mathrm{U}^{3}$ \\ ${ }^{1}$ Department of Earth Sciences, Olabisi Onabanjo University, Ago-Iwoye, Nigeria \\ ${ }^{2}$ Department of Geosciences, University of Lagos, Lagos, Nigeria \\ ${ }^{3}$ Department of Geology and Mineral Science, University of Ilorin, Ilorin, Nigeria \\ Correspondence: Bayewu, Olateju O., Department of Earth Sciences, Olabisi Onabanjo University, Ago Iwoye, \\ Nigeria. Tel: 234-805-707-0285. E-mail: tejubpositive@yahoo.com
}

Received: October 8, 2014 Accepted: October 20, 2014 Online Published: November 25, 2014

doi:10.5539/jgg.v6n4p140 URL: http://dx.doi.org/10.5539/jgg.v6n4p140

\begin{abstract}
This study was carried out to determine the anisotropic properties of parts of the Southwestern Basement Complex of Nigeria in Ijebu Igbo, which is underlain by migmatite gneiss and older granites.

The surface water level (SWL) of 107 hand-dug wells were measured to determine the groundwater flow direction of the area. Thirty Azimuthal Resistivity Survey (ARS) were investigated along four azimuths; $0^{\circ}, 45^{\circ}, 90^{\circ}$, and $135^{\circ}$ to determine the electrical anisotropy, the trend of fractures and their behavioural pattern with depth. The quantitative interpretation of the Radial Vertical Electrical Sounding (RVES) curves involved the use of partial curve matching, and computer iteration using WINRESIST program.
\end{abstract}

The results of the wells measurement showed that the major directions of groundwater flow pattern of the study area are N-S and E-W while the NE-SW or NW-SE are less prominent. Geo-electric interpretation of the RVES data revealed the area to be underlain by three geo-electric layers; Top soil, $(160 \Omega \mathrm{m}-1454 \Omega \mathrm{m})$, lateritic Horizon clayey/sandy clay horizon, $(22 \Omega \mathrm{m}-160 \Omega \mathrm{m})$, and weathered/fresh Basement $(421 \Omega \mathrm{m}-3122 \Omega \mathrm{m})$ with depth to fracture systems ranging from $6.3-54 \mathrm{~m}$. The reflection coefficient observed ranges from $0.6-0.98$. The direction of electrical anisotropy was derived from the polar plot and lies predominantly at NW-SE and E-W, N-S while the NE-SW is less prominent. Coefficient of anisotropy ranges between 1.09 and 1.36 with a mean of 1.2. The apparent anisotropic graphs show the behavioral pattern of the fracture with depth and reveal that the predominant fractures in the area are closing with depth.

The orientation of geologic structures from the study area showed an E-W, and NW-SE direction and this corresponds to the directions of the electrical anisotropic polygons. The fractures are known to be complex and in turn interconnected, hence a fracture controlled flow.

Areas with low bedrock resistivity, thick overburden, presence of two interconnected anisotropy polygon directions and high co-efficient of anisotropy indicate intense fracturing, thus, a potential sites for the drilling of water borehole.

Keywords: resistivity anisotropy, groundwater flow direction, anisotropy polygon, coefficient of anisotropy, fracture direction

\section{Introduction}

Electrical resistivity anisotropy for geological prospecting has not been extensively used in surface geophysics despite the usefulness of electrical methods for detecting fluid - filled fractures (Mamah and Ekine, 1989, Olasehinde and Bayewu, 2011). Surface geological mapping and remote sensing methods which include aerial photographs, Side Looking Airborne Radar (SLAR) and Landsat sensors are commonly employed in the identification of structural elements (Okurumeh and Olayinka, 1998). However, the usefulness of geological mapping is limited only to areas where the rocks outcrop. In Southern Nigeria, remotely sensed data is of poor quality due to the masking effect of dense clouds, thick vegetation and short SLAR wavelength with limited look 
direction of SLAR (Gelnelt, 1978; Koopman's 1982; Ezenabor, 1985b). There is also the problem of accurate correlation of identified structural features on the basis of air photos and actual position on the ground due to the position fixing error (Ezenabor; 1985a). Conversely, surface geophysical techniques can be an invaluable tool in mapping the structural features of the concealed crystalline basement rocks (Olorunfemi and Opadokun, 1987) and in the detection of microfabrics resulting from basement tectonic in sedimentary terrain (Mamah and Ekine, 1989). Electrical anisotropy of crystalline basement rocks is often attributed to structural elements like foliations, joints and fractures (Billings 1972; Malik, et al., 1983). It has been shown by Odeyemi, et al., (1985); Beeson and Jones, (1988); Esu, (1993) and Edet et al., (1994) that the well yield and its direction flow in fractured rocks is directly related to the density, frequency, orientation and inter-connection of structural features at depth.

Electrical anisotropy is an important subject, not only to the geophysicists and geologists, but also to the petrophysicist, drillers, stratigraphers, as well as reservoir engineers. Where electrical anisotropy exists, convenient assumptions fail, actual geological depths and structures are wrongly imaged, petrophysical parameters are wrongly estimated and drilling activities becomes more problematic because of loss in circulation of drilling fluids. There has been growing need and interest in the application of azimuthal resistivity surveys (ARS) using various electrode adaptations to locate, characterize, and identify the directional properties of anisotropic rock mass in the earth's surface. In using azimuthal resistivity survey, any observed change in apparent resistivity $\rho$ a is interpreted as an indication of fracture anisotropy, which in most cases might also be produced by the presence of a dipping bed or inhomogeneities or lateral changes in apparent resistivity (Watson and Barker, 1999, Busby, 2000). Several authors (Habberjam and Watkins, 1967; Barke 1981; Taylor and Fleming, 1988; Skjernaa and Jorgensen, 1993, Carlson et al 1996 and Busby, 2000) have worked on the use of different array adaptations in azimuthal resistivity surveys (ARS) to characterize the electrical anisotropy of different rock types in terms of the anisotropic parameters viz: the direction and coefficient of electrical anisotropy $(\lambda)$. In each case, the authors claim the effectiveness of one electrode adaptations to the other in characterizing the electrical anisotropy of the rock units.

Azimuthal resistivity is a modified resistivity method where the magnitude and direction of the electrical anisotropy are determined. An electrode array is rotated about its centre so that the apparent resistivity is observed for several directions (Taylor and Fleming, 1988). It is generally assumed that the anisotropy is caused by the presence of fluid-filled fractures in a relatively resistive rock or soil. Azimuthal resistivity has been used to determine fracture geometry in crystalline rocks and glacial till by Lane et al (1995), Carlson et al (1996a and b), Hansen and Lane (1996), Chapman and Lane (1996) and Baker and McIntyre (2001). Hansen and Lane (1996), also characterize the porosity and aperture of high-angle fractures using the azimuthal resistivity method.

One of the key problems with the azimuthal resistivity method is its sensitivity to lateral heterogeneities. A site exhibiting significant lateral changes in resistivity can produce azimuthal resistivity measurements where the effects of anisotropy are entirely masked by the effects of heterogeneity. (Hansen and Lane,1996).

Azimuthal resistivity surveys (ARS) are often conducted to determine the principal direction of electrical anisotropy. The identification and characterization of fractures is important in rocks with low primary (or matrix) porosity because the bulk porosity and permeability are determined mainly by the intensity, orientation, connectivity, aperture, and infill of fracture systems (Skyernaa and Jorgensen, 1993). Azimuthal resistivity surveying has been adopted by Slater et al, (2006), Skyernaa and Jorgenson, (1993) and Taylor and Fleming, (1988) as a technique for determining the principal directions of electrical anisotropy. Typically, any observed change in apparent resistivity with azimuth is interpreted as invocative of anisotropy (generally fracture anisotropy). It is often assumed that the principal directions of hydraulically conductive fracture measured from electrical anisotropy may be inferred from the measured electrical anisotropy (apparent resistivity ( $\rho$ a) as a function of azimuth and the strike of the fracture), since both current flow and groundwater are channelled through fractures in the rock.

The need for the development of groundwater resources for the potable use in the Ijebu Igbo metropolis requires understanding the anisotropy, directional connectivity and porosity of the fracture system so as to identify a viable aquifer system which essential for sustainable development in this region. Therefore, the aim of this work is to carry out geophysical investigation of the area so as to study the resistivity anisotropy characteristics of the subsurface rocks in the area in order to delineate the fracture directions, this will help in studying its influence on the direction of ground water flow and also to study the behaviour of the fracture with depth.

\section{Location and Geology of the Study Area}

The study area (Figure 1) lies within latitude $6^{0} 57^{\prime} \mathrm{N}$ to $7^{0} 00^{\prime} \mathrm{N}$ and longitude $3^{0} 58^{\prime} \mathrm{E}$ to $4^{0} 00^{\prime} \mathrm{E}$ with an area extent of approximately 27.4 square kilometres. The topography (Figure 1) of the study area according to Akanni 
(1992), results from the geomorphic processes that have shaped the terrain. It is characterized by a tropical climate with alternating wet and dry seasons. The area has double maximum of rainfall and the peak being June and September while the dry season last from November to early March (Akanni, 1992). The temperature ranges between $32^{\circ} \mathrm{C}-21{ }^{\circ} \mathrm{C}$ throughout the year. Due to the climate conditions of the area, the vegetation is of typical rainforest vegetation. The drainage pattern is dendritic. The relief of the study environment is moderately high and it has a gradient of approximately 1/600, an indication of a nearly flat topography. Shanu (1991) and Adeyemi (1995) noted that landform such as relief, surface morphology and drainage systems depends to a large extent on the difference in the composition of rocks and the frequency of joints and fissures in rocks. This study area is easily accessible through a series of interconnecting minor roads, footpaths and a few major roads. It is approximately $25 \mathrm{~km}$ north of Ijebu-ode, $7 \mathrm{~km}$ to Ago-Iwoye and $5 \mathrm{~km}$ drive to Oru-Ijebu.

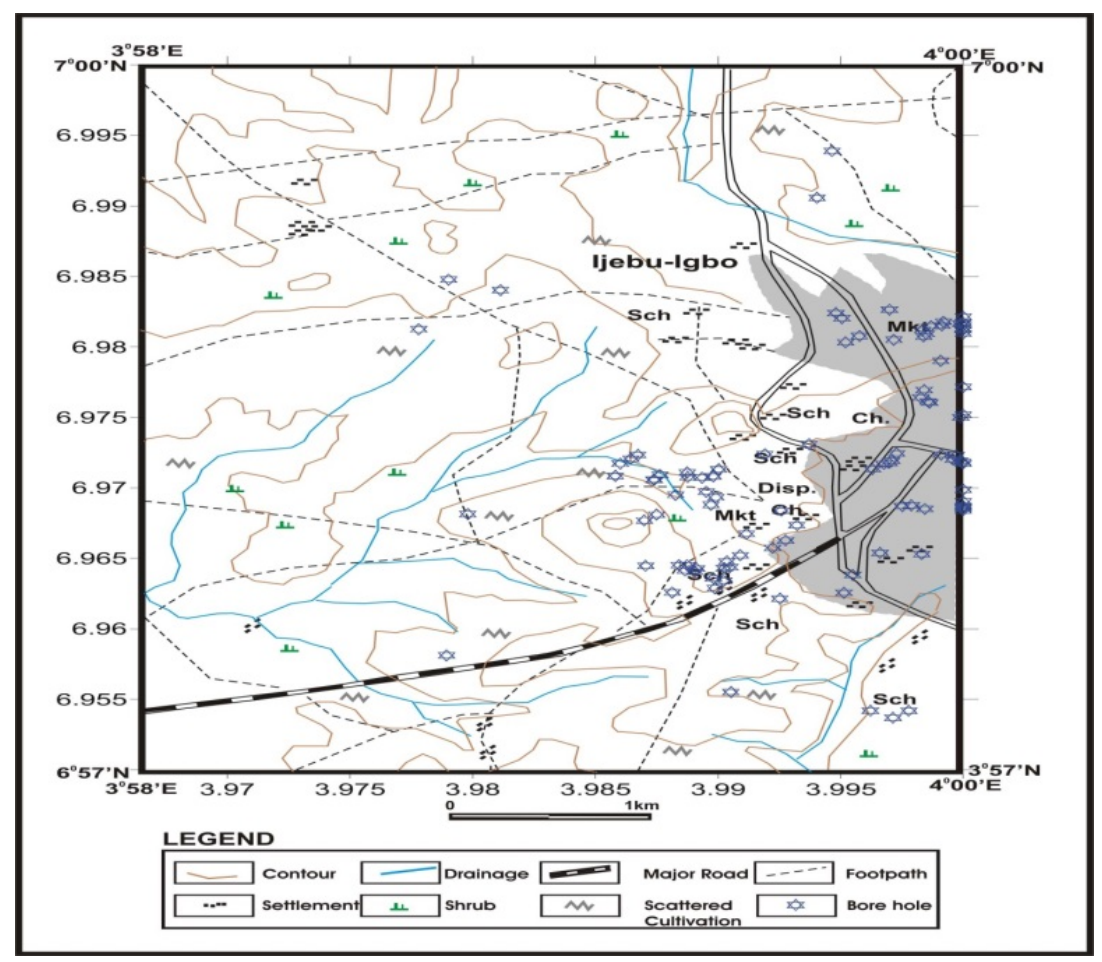

Figure 1. Location Map of the study area showing the road network, settlement draining pattern and vegetation

Geologically, the study area is part of the Southwestern Basement Complex of Nigeria. The area study is representative of both the migmatite gneiss complex and the older granite, which shows structural disposition (Rahaman, 1976). The migmatite-gneiss complex occupies the Southwestern part and the South-eastern part of the area while older granite occupies the north, east and some parts of the western area (Figure 2).

The Basement Complex serves as poor aquifers when in unaltered state because of their low porosity and permeability (Rahaman, 1976). The occurrence of groundwater in this environment is largely due to occurrence of secondary porosity and permeability resulting from weathering and fracturing of the rocks. The nature and thickness of the overburden also play important role on the availability of groundwater. If the overburden occur as loose aggregate or as sands, it allows percolation of water into it, so the extent of such overlying materials, thus indicate the amount of groundwater in the subsurface (Olorunfemi et al, 1999).

The types of structure observed on the study area include foliations, joints and veins. The plot of rose diagram of structural features in the study area revealed that the veins and foliations observed on the field mapped are generally concordantly emplaced and they show a general orientation of NW-SE, (figure 3a), unlike the joints which are in the NE-SW direction as shown in figure 3b, this implies that the forces that caused the formation of the vein and foliation moved in the same direction while that of the joint is perpendicular to them. The strike and dip for foliation measurements in this area were plotted with stereonet and are shown in figure 4 . This reveals that the foliations are predominantly dipping westerly and they have a gentle dip. 


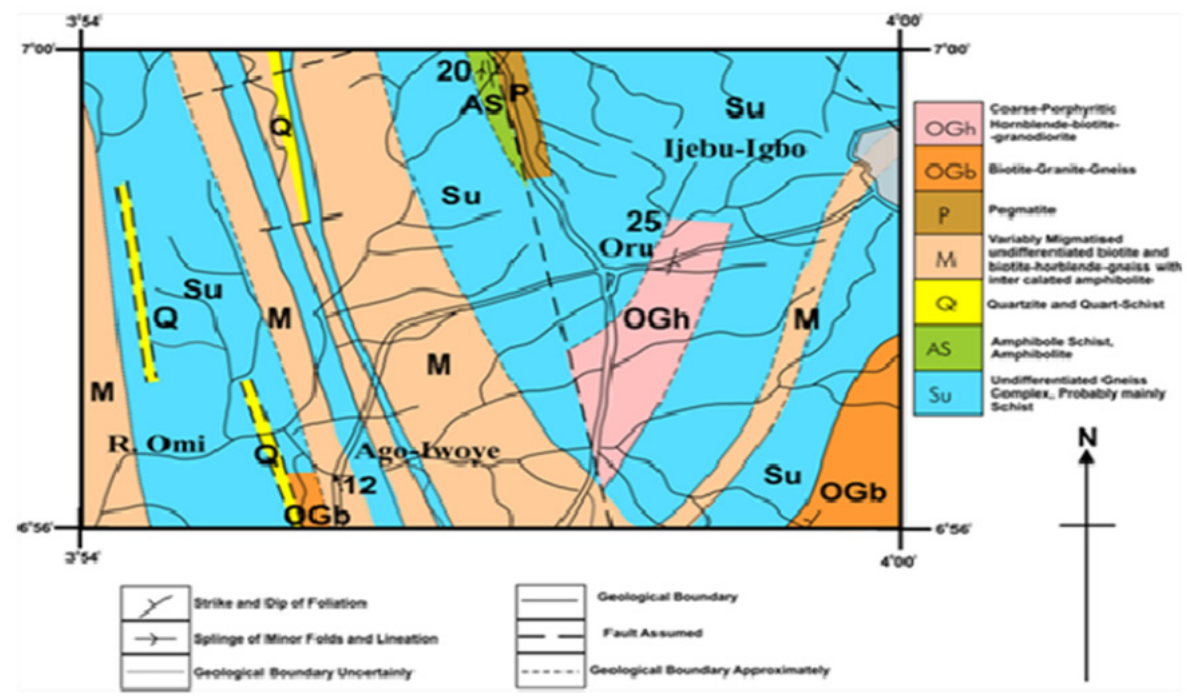

Figure 2. Geologic Map of the study area

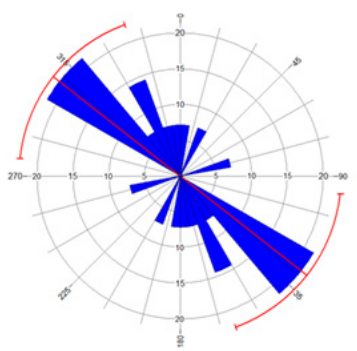

a

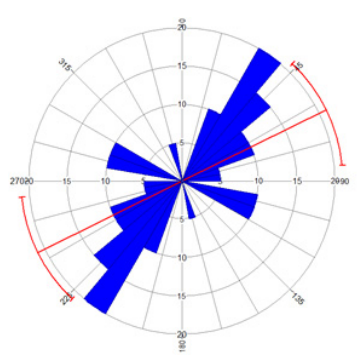

b

Figure 3. a) Rose diagram for veins and foliations of the rocks in the study area. b) Rose diagram for joints in the study area

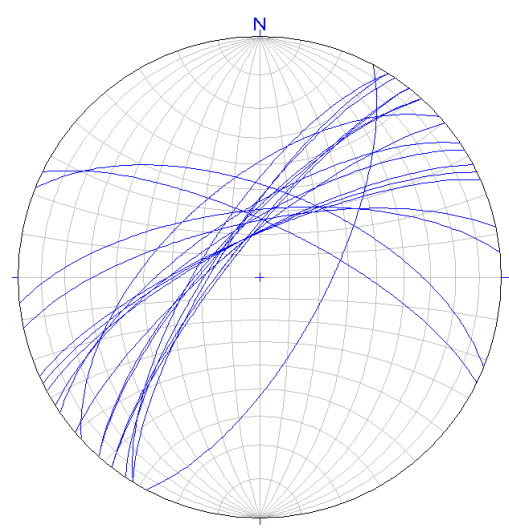

Figure 4. Rose diagram for foliations in the study area

\section{Methodology}

The investigation was carried out in two stages; measurement of Surface Water Level (SWL) and geophysical investigation. SWL were measured from one hundred and seven (107) hand dug wells at different locations within the study area. This was done in order to determine the flow direction of groundwater in the area. This will help in 
determining the prevalence fracture direction within the underlying rock of the area, since these fractures have a prominent influence on the direction of groundwater flow, especially in the basement terrain. These measured well points are shown in figure 1. The groundwater flow direction was determined by the plot of these SWL.

Electrical resistivity method is one of the artificial source geophysical techniques that utilize current from a direct, cumulated or low frequency alternating current source of electromotive force (E.M.F.) to depict the earth's content.

In the simple case of a single set of parallel water-filled fractures, the bulk specific resistivity $\rho_{\mathrm{v}}$ at right angle to the fractures is greater than the bulk specific resistivity $\boldsymbol{\rho}_{\mathbf{I}}$ parallel to the fractures. The resistivity of the system may be described by the parameters:

$$
\rho_{m}=\sqrt{\rho_{v} \rho_{l}} \text { and } \lambda=\sqrt{\rho_{v} / \rho_{l}}
$$

Where $\boldsymbol{\rho}_{\mathrm{m}}$ is the mean bulk resistivity and $\lambda$ is the coefficient of anisotropy and is greater than unity (Keller and Frischknecht 1966). In the case of a single set of vertical fractures (Figure 5a), the potential distribution in the horizontal plane is given by:

$$
V=\frac{I \rho_{m}}{2 \pi r}\left(\cos ^{2} \theta+\lambda^{2} \sin ^{2} \theta\right)^{-1 / 2}
$$

Where $\mathrm{V}$ is the potential at point $\mathrm{M}=(\mathrm{x}, \mathrm{y}, 0)$ with the polar coordinated $(\mathrm{r}, \theta, 0)$ and $\mathrm{I}$ is the magnitude of the input at point $\mathrm{A}$. Equipotential lines are found by keeping $\left(a^{2}+b^{2}=c^{2} \cos ^{2} \theta+\lambda^{2} \sin ^{2} \theta\right)$ constant in this equation. It is seen that the equipotential lines are ellipses with long axes $\mathrm{V}_{\mathrm{x}}$ parallel with the strike of the fractures $\left(\theta=0^{\circ}\right)$, and short axes $\mathrm{V}_{\mathrm{y}}$ perpendicular to the fractures $\left(\theta=90^{\circ}\right)$. Thus the potential has the greatest magnitude in the direction with the smallest value of the true resistivity, i.e. parallel to the fractures. This is the paradox of anisotropy (Keller and Frischknecht 1966). If the fractures are not vertical, but dip at an angle $\alpha$ (Figure $5 \mathrm{~b}$ ) eq. 2 is transformed to:

$$
V=\frac{I \rho_{m}}{2 \pi r}\left(\cos ^{2} \theta+\left(\cos ^{2} \alpha+\lambda^{2} \sin \alpha\right) \sin ^{2} \theta\right)^{-1 / 2}
$$

Equipotential lines in the $\mathrm{x} y$-plane still form ellipses whose long axes have not changes from the case with vertical fractures, while their short axes increase with decreasing $\alpha$. For horizontal fractures $V_{y}=V_{x}$.

Field measurements employ four electrodes in an array (Figure 5c); two current electrodes, A and B, with equal, but oppositely directed currents $+\mathrm{I}$ and $-\mathrm{I}$ and two potential electrodes, $\mathrm{M}$ and $\mathrm{N}$, between which $\Delta \mathrm{V}$, the difference in their potential, can be measured. In the Schlumberger array, which has been used here, the four electrodes are symmetrically arranged around the center and $\mathrm{L}>>\mathrm{a}$.

If the idealized situation with vertical parallel fractures is considered, eq. 2 becomes:

$$
\frac{\Delta V}{I} K=\rho_{a} \sim \rho_{m}\left(\cos ^{2} \theta+\lambda^{2} \sin ^{2} \theta\right)^{-1 / 2}
$$

Where $K=\frac{\pi L^{2}}{4 a}$ is the geometric factor for Schlumberger configuration.
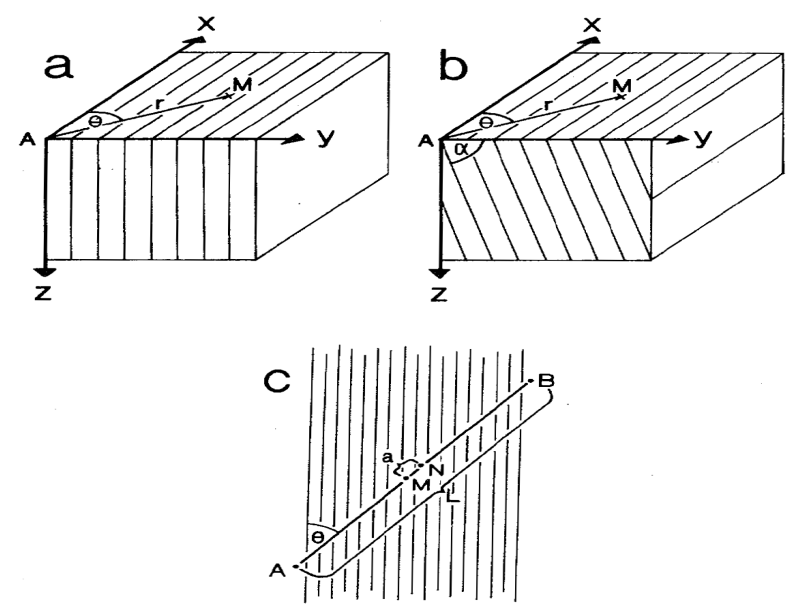

Figure 5. Coordinate configuration for (a) vertical and (b) dipping fractures; current input at A, potential determination at M. (c) Plan view of the azimuthal resistivity survey array, current electrodes at A and B, potential electrodes at M and N.(after Keller and Frischknecht 1966) 
When the apparent resistivities $\rho_{\mathrm{a}}$ in different directions, are plotted as radii, they generate an anisotropy figure; this is an ellipse in the case of simple fractures. A narrow ellipse with high long to short axis ratio $\alpha / b$ suggests a vertical continuous fracture with high aperture whereas broad ellipses develop from dipping and/or short fractures with low connectivity or low aperture. The effect of multiple fracture sets is additive and combine to form a more complicated anisotropy figure (Taylor and Fleming 1988).

This method of prospecting is the most widely used geophysical method for exploration of groundwater bearing formation, stratigraphical correlation in oil fields and also for prospecting conductive ore bodies. Resistivity methods involves the study of horizontal and vertical discontinuities in the electrical properties of the ground and also the detection of 3-Dimentional bodies of anomalous conductivity and it is also the most important method in groundwater exploration and accounted for about $80 \%$ of the total groundwater in Nigeria.

The electrical resistivity method involves various physical parameter of the area study which includes the resistivity and geoelectrical parameter, it is affected by various factors which include porosity and salinity, (Olayinka 1990).

Thirty (30) Azimuthal Resistivity Survey (ARS) which involved the measurements of electrical resistivity along four azimuths, namely; $0^{\circ}, 45^{\circ}, 90^{\circ}$ and $135^{\circ}$ were carried out in the area. An Ohmega Resistivity meter was used for resistivity measurements and readings were taken automatically and the results are averaged continuously thus increasing signal to noise ratio. The Schlumberger configuration was employed, with a maximum current electrode spacing $\mathrm{AB} / 2$ of $100 \mathrm{~m}$. The apparent resistivity $(\rho \mathrm{a})$ values were derived as the product of the resistance read from the resistivity meter and its corresponding geometric factor (Zohdy, 1974). These were then plotted against their corresponding half electrode spacing $(\mathrm{AB} / 2)$ on a bi-logarithmic paper. These field curves were manually interpreted initially by partial curve matching using master curves (Zohdy, 1974). Geoelectric parameters obtained from the partial curve matching interpretation were later used as an input model for computer-assisted iteration of WINRESIST program.

The reflection coefficients (r) of the study area were calculated using the method of Olayinka (1996); Bhattacharya and Patra (1968) and Loke (1999):

$$
r=(\rho n-\rho(n-1)) /(\rho n+\rho(n+1))
$$

Where $\rho_{\mathrm{n}}$ is the layer resistivity of the nth layer (i.e the last layer) and $\rho_{(\mathrm{n}-1)}$ is the layer resistivity overlying the nth layer.

The result of the maximum current electrode spacing was used to produce the iso-resistivity map. The azimuthal apparent resistivity was measured for a given $\mathrm{AB} / 2$ separations and was plotted along their corresponding azimuths to generate anisotropy polygons for the area. The major or longest axis of the ellipse, observed in such anisotropy polygons, gives the direction of the fracture. The co-efficient of anisotropy $(\lambda)$ (designated here as the degree of fracturing) is calculated from each anisotropy ellipse (fitted through each polygon) using the relationship

$$
\lambda=a / b
$$

where $\mathrm{a}$ and $\mathrm{b}$ are the major (longest) and minor (shortest) axes of the element. A useful parameter of anisotropic medium is the co-efficient of apparent anisotropy $(\lambda a)$ and is calculated by:

$$
\lambda a=\rho t / \rho s
$$

where $\rho t$ is the transverse resistivity which is perpendicular to the strike direction of the rock while $\rho s$ is the longitudinal resistivity which is along the strike direction of the rock. All the calculated $\lambda$ a values are then plotted against their corresponding $\mathrm{AB} / 2$ separations. The behavior of rock fracturing at various depths can thus be understood qualitatively from the variation of $\lambda$ a with depth (Habberjam, 1975).

\section{Results and Discussion}

To enhance the RVES interpretation, groundwater hydraulic head data from about 107 hand dug wells were collected and used to generate the groundwater flow contour map (Figure 6). The surface water level was calculated from the difference between the well water depth and the elevation from the Google Earth software. The SWL ranged from $58 \mathrm{~m}$ to $108 \mathrm{~m}$ above sea water level, the highest SWL is found in the north central part of the map which estimated to range from between $100 \mathrm{~m}$ to $108 \mathrm{~m}$ while major portions of the map were characterized by SWL values ranging from $92 \mathrm{~m}$ to $96 \mathrm{~m}$. The map showed that the groundwater flow directions are southerly and easterly while the groundwater gathers centrally in the study area; this however serves as the point of recharge in the area (Figure 6).

The result of the RVES data for the study area were plotted (Figure 7), this shows the evidence of anisotropy as 
the VES curves vary in geometry. The RVES curves were further iterated for the sounding interpretation along the $0^{0}$ azimuth. The iterated curves revealed 4 to 5 layer curve types. The four layer curves include the KH (i.e., $\mathrm{p} 1<\mathrm{p} 2>\mathrm{p} 3<\mathrm{p} 4$ ), HA (i.e., $\mathrm{p} 1>\mathrm{p} 2<\mathrm{p} 3<\mathrm{p} 4)$ and $\mathrm{QH}$ (i.e., $\mathrm{p} 1>\mathrm{p} 2>\mathrm{p} 3<\mathrm{p} 4)$ while the remaining five layer curves consists of the QQH $(\mathrm{p} 1>\mathrm{p} 2>\mathrm{p} 3>\mathrm{p} 4<\mathrm{p} 5)$, and $\mathrm{AKH}(\mathrm{p} 1<\mathrm{p} 2<\mathrm{p} 3>\mathrm{p} 4<\mathrm{p} 5)$.

The isopach map of the area is presented in figure 8 . The overburden thickness ranges from $0.6 \mathrm{~m}$ to $61.5 \mathrm{~m}$. The major part of the area is characterized by overburden greater than $15 \mathrm{~m}$. However, the thickness shows an increase towards the southwestern part. The study area therefore shows a promising groundwater potential in supporting both borehole and hand dug well. The result of the bedrock iso-resistivity map is shown in figure 9 . The bedrock resistivity values range from $1467.3 \Omega \mathrm{m}$ to $27,457 \Omega \mathrm{m}$ and shows an appreciable agreement with the isopach map. The resistivity values also increase towards the southwestern direction in this area. However, the reflection coefficient map of the area shows that the values range from 0.5 to 0.9 . (Figure 10), the values increase to the southwestern direction.

The geoelectric units are typical of those identified within the weathering profile developed upon crystalline basement rocks in low latitude environments. These are the topsoil, the regolith (an admixture of clay, sand clay, and clayey sand) and partially decomposed rock over the fresh bedrock. Table-3 gives a summary of the depth to the bedrock obtained from the sounding interpretation for the $0^{0}$ azimuth.( the manuscript did not contain any table, therefore this statement highlight in blue colour should be remove totally).

The iterated curves plotted for the direction of $0^{\circ}$ along the profile lines were used to produce the geoelectric section. The geoelectric section 1 (figure 11) revealed that the line is made up of 5 layers; the inferred lithology of the first layer is the top soil and has resistivity range of 303.5 to $578.6 \Omega \mathrm{m}$ and a thickness range of $1 \mathrm{~m}$, having relatively lower thickness to that of layer 2, 3, and 4 which make up the sand and clayey sand layers and have thicknesses of $1.4,6,8$, and $8.1 \mathrm{~m}$ respectively. The fifth layer is unto infinity as revealed by calculation form the reflection coefficient is the fractured/ fresh basement and has a resistivity range of $1467 \Omega \mathrm{m}$ to $27457 \Omega \mathrm{m}$. The reflection coefficient ranges from 0.51 to 0.96 .

The anisotropic polygons plotted from the azimuthal resistivity survey data are shown in figure 12. From these polygons, the inferred structural trends in this area are N-S, NE-SW, NW-SE and W-E while some stations also show interconnection of two structure/fracture directions. The results of the directions from the polygons when compared to the measured structural trend of the fractures and foliations showed a significant agreement with each other.

The co-efficient of anisotropy $(\lambda)$ values in this area vary from 1.09 to 1.61 with a mean of 1.2. It has been shown to have the same functional form as permeability anisotropy to a first order (Bespolov et al., 2002). Thus, a higher coefficient of anisotropy $(\lambda)$ implies higher- permeability anisotropy. The values do not show any particular interrelation with the inferred structural trends. There is no significant difference between the co-efficient of anisotropy (1.20) obtained in this study which is basically a basement complex terrain when compared with that reported in other igneous terrains around Okeho, southwestern Nigeria which is 1.21 (Okurumeh and Olayinka, 1988). The depth to bedrock is not strongly dependent on the co-efficient of anisotropy. However, localities with low mean bedrock resistivity and a high co-efficient of anisotropy may indicate intense fracturing and such localities are potential sites for the drilling of water borehole. 


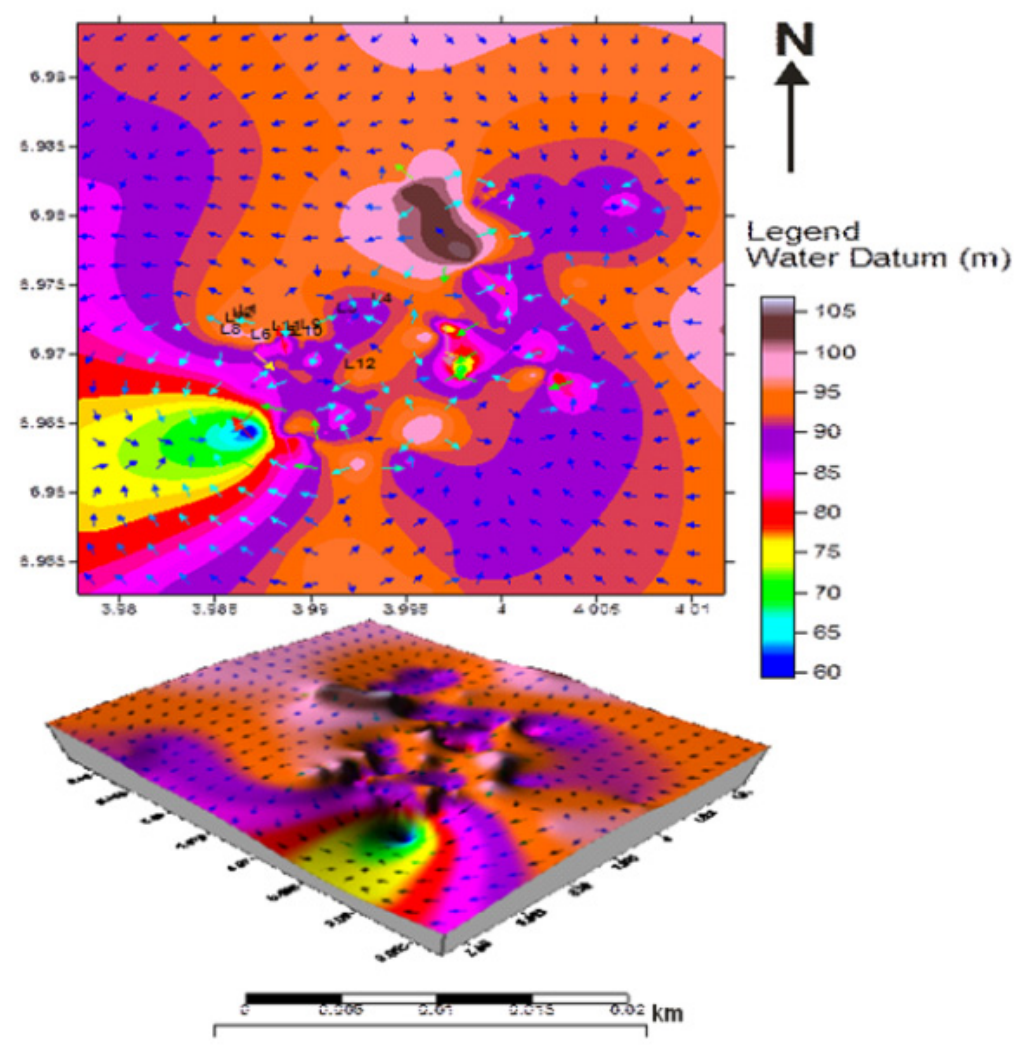

Figure 6. Groundwater flow map of the study area

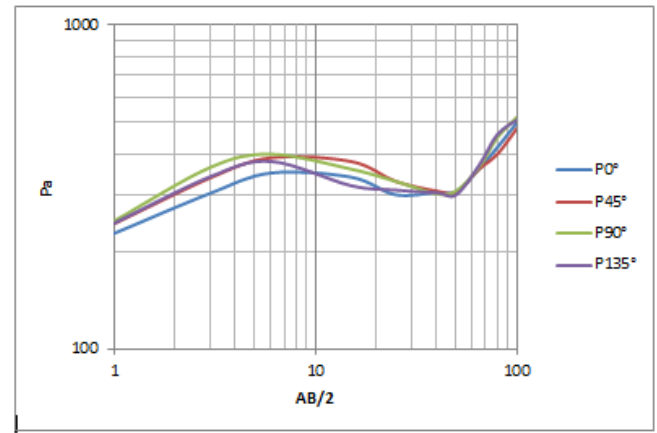

RVES 3

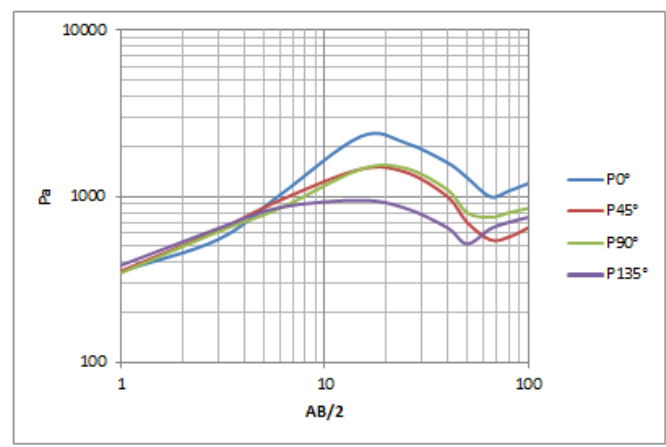

RVES 1

Figure 7. Some of the RVES curves of study area 


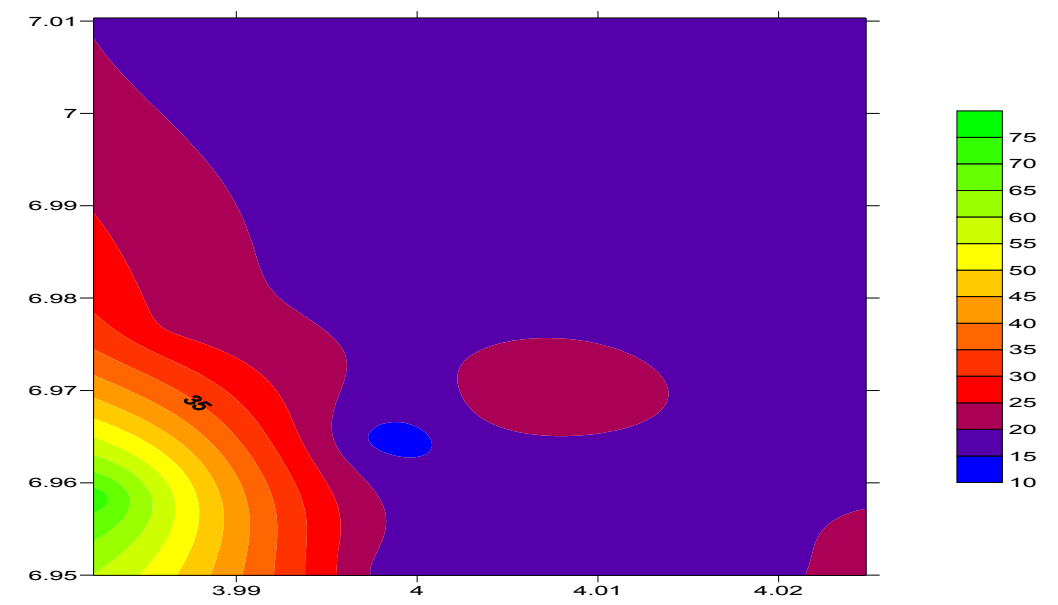

Figure 8. Isopach Map of the Study Area

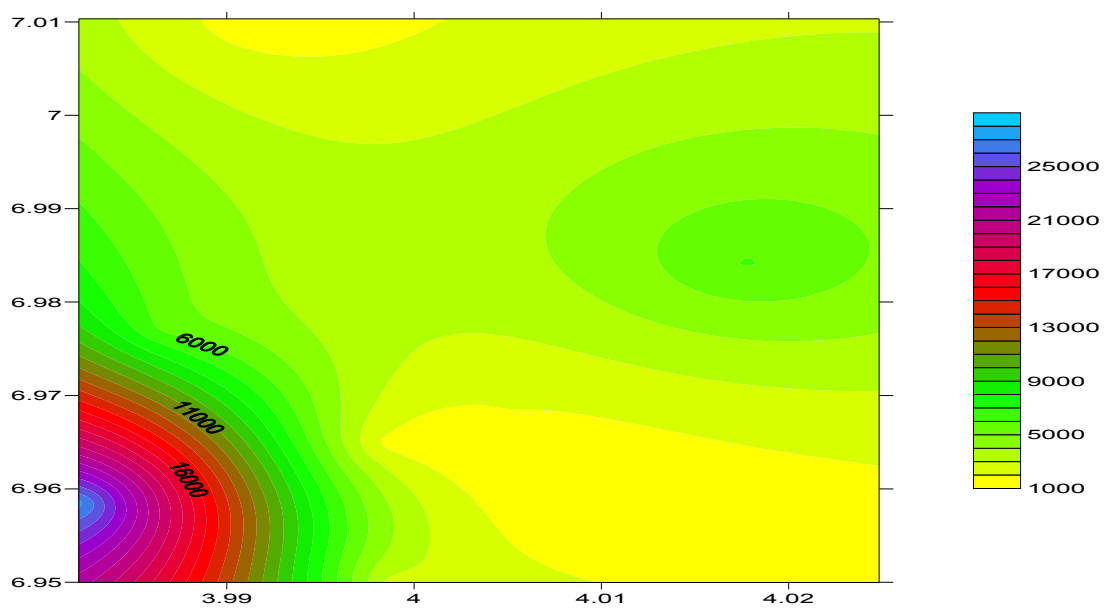

Figure 9. Iso-resistivity map showing the resistivity of different parts of the area

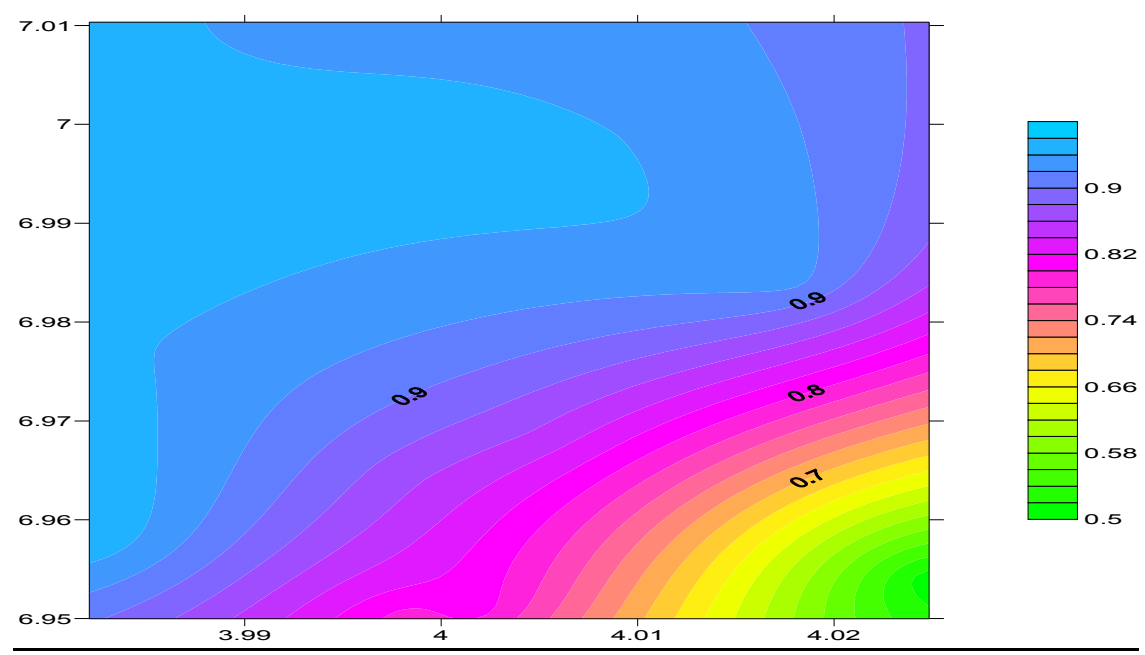

Figure 10. Reflection co-efficient Map of the Study Area

The results obtained from the plot of the coefficient of apparent anisotropy with depth (Figure 13) revealed two results; some areas showed apparent anisotropy plots closing with depth (figure 13a) which consequently outlines its support for engineering activities and unsuitability for hydrogeological activities while some areas showed the plot of apparent anisotropy opening with depth (figure 13b) which outlines its support for hydrogeological activities and reveals its unsuitability for engineering activities. 


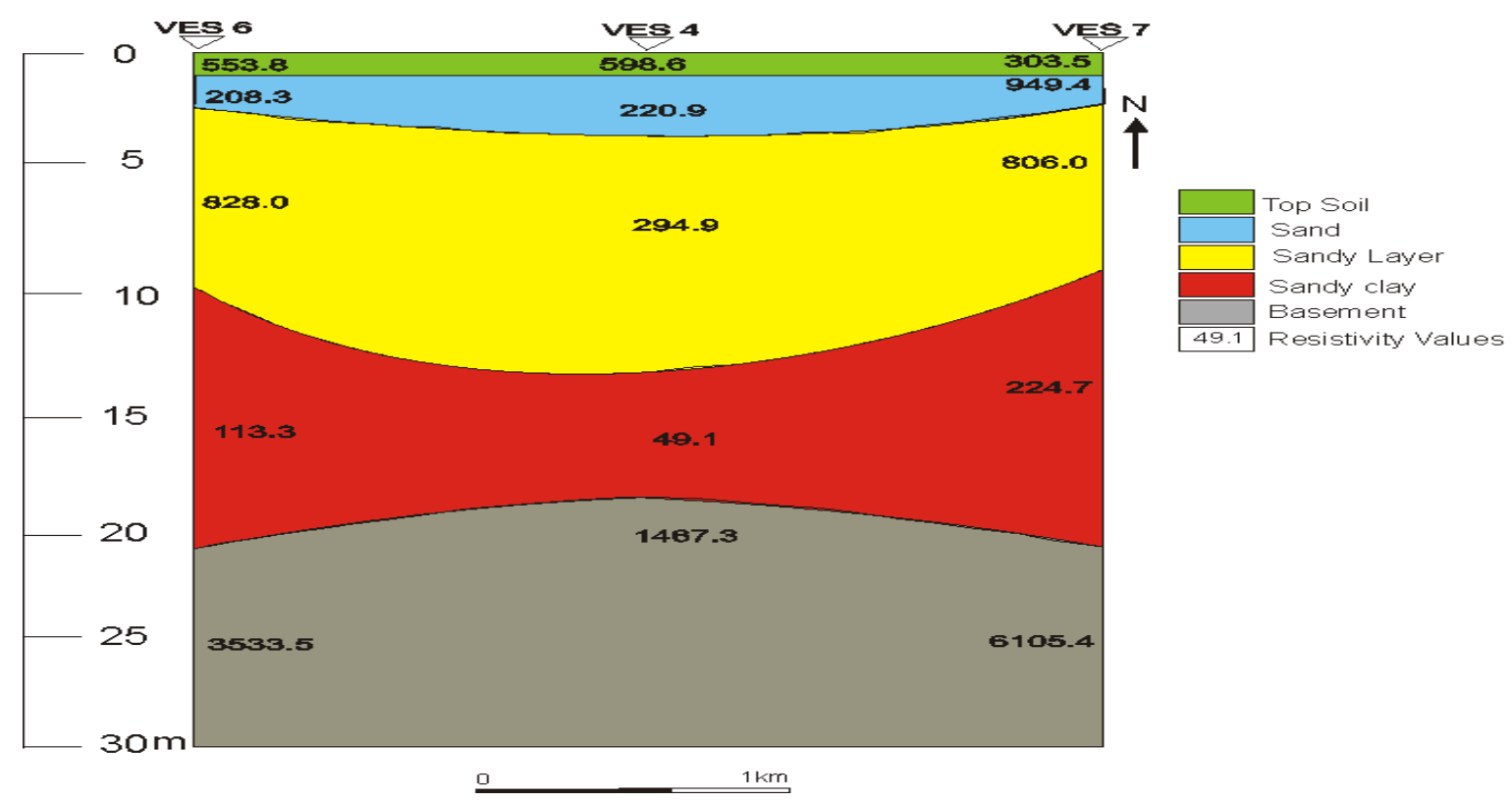

Figure 11. Geoelectric Section

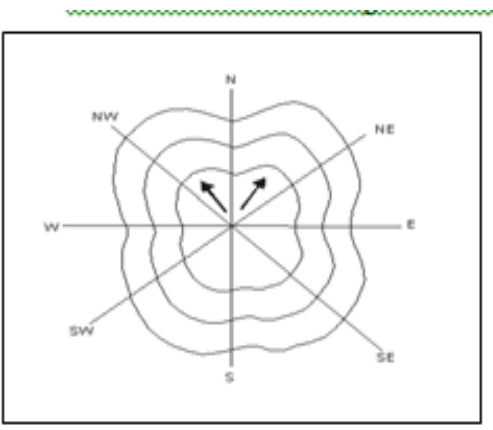

Station 2

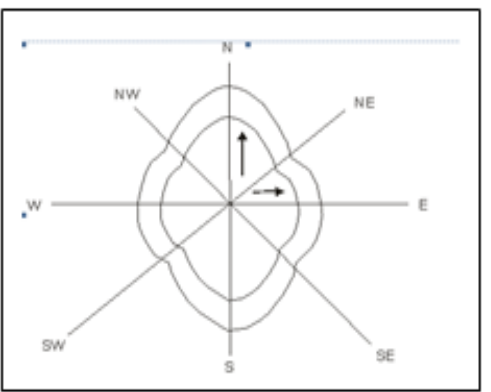

Station 14

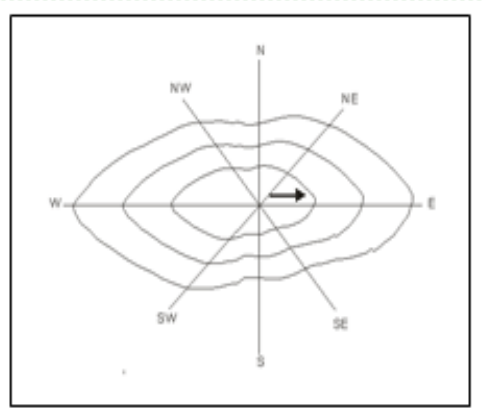

Station 7

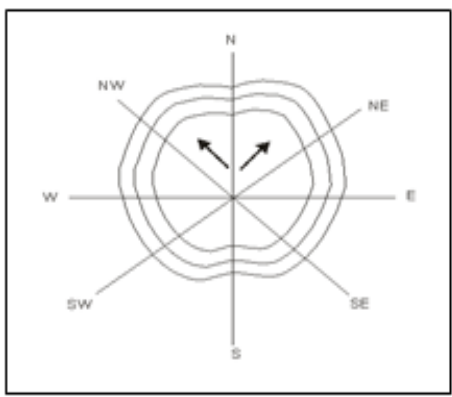

Station 20

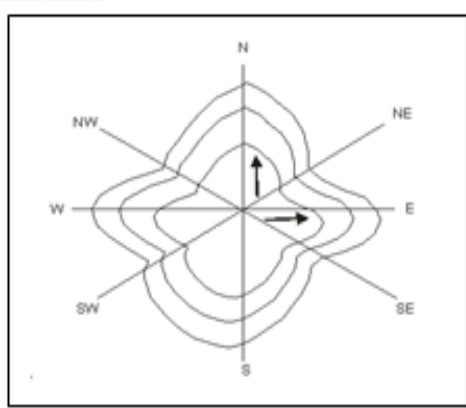

Station 10

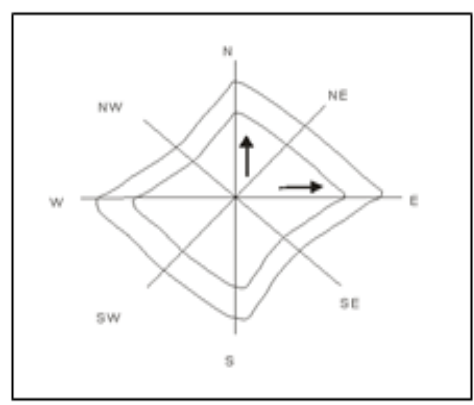

Station 25

Figure 12. The plots of some of the Anisotropy Polygons of the study area 

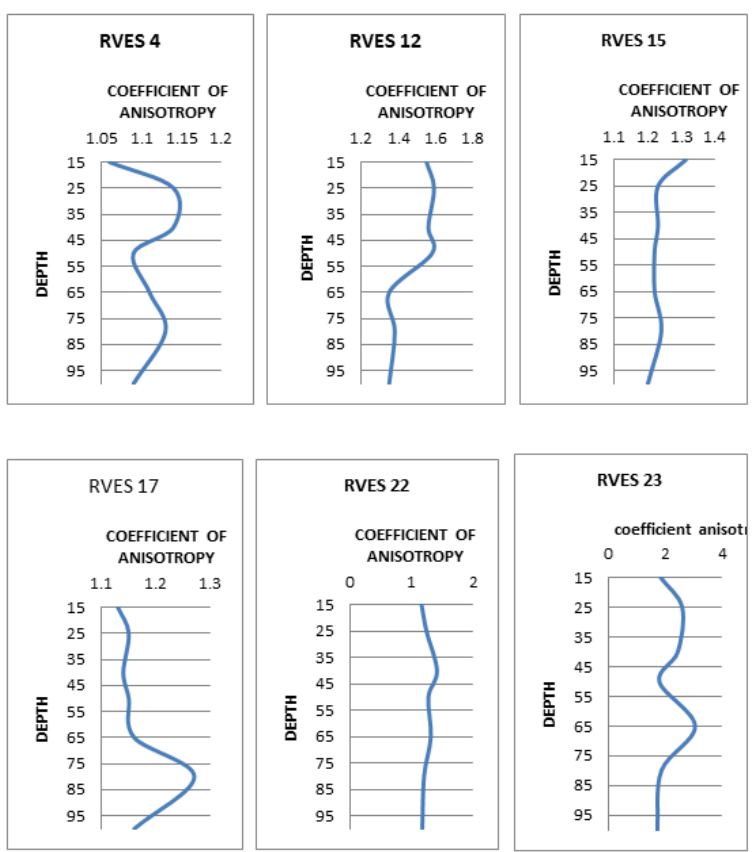

Figure 13. The plot of the coefficient of apparent anisotropy closing against depth for some RVES stations in the study area
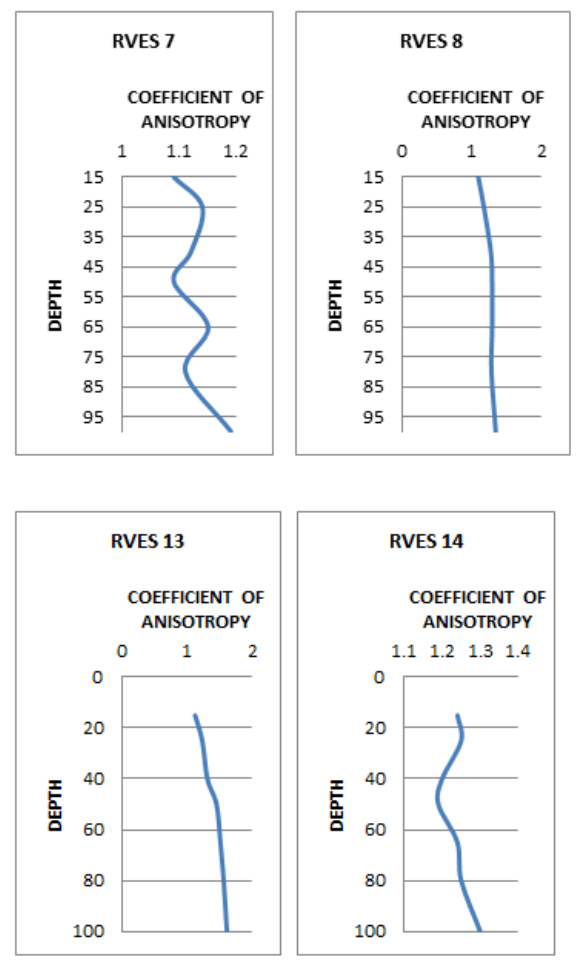

Figure 13b. The plot of the coefficient of apparent anisotropy opening against depth for some RVES stations in the study area

The depth to bedrock is not strongly dependent on the co-efficient of anisotropy. However, areas with low bedrock resistivity, low reflection coefficient, thick overburden, presence of two interconnected anisotropy 
polygon directions and high coefficient of anisotropy may indicate intense fracturing, thus, potential sites for the drilling of water borehole. Based on this, it can be inferred that the southern and the southern eastern parts of the map exhibit the highest ground water potential while the north and northwestern parts exhibit less ground water potential.

\section{Conclusion}

Azimuthal apparent resistivity measurements are potentially a powerful method for characterizing fractured rock since they measure parameters which cannot be obtained from traditional profile measurements. Localities with low mean bedrock resistivity and a high coefficient of anisotropy may indicate intense fracturing and such localities are potential sites for the drilling of water-supply boreholes. This method seems to provide a useful tool for the identification of fracture systems and related anisotropic conductivity patterns in jointed crystalline rocks. This will help to identify the pathways of contaminant transport and will also be important for groundwater protection and waste disposal.

\section{References}

Beeson, S., \& Jones, C. R. C. (1988). The combined EMT/VES geophysical method for siting boreholes. Ground Water, 26, 54-63. http://dx.doi.org/10.1111/j.1745-6584.1988.tb00367.x

Bhattacharya, P. K., \& Patra, H. P. (1968). Direct Current Geoelectric Sounding Methods in Geochemistry and Geophysics. Elsevier, Amsterdam, 135p.

Billings, M. P. (1972). Structural Geology (3rd ed). Prentice-Hall. 309p.

Chapman, M. J., \& Lane, J. W. (1996). Use of directional borehole radar and azimuthal square-array D.C. resistivity methods to characterize a crystalline-bedrock aquifer: SAGEEP 1996 Conference, Environ. Eng. Geophys. Soc. Proceedings, 833-842.

Edet, A. E., Teme, S. C., Okereke, C. S., \& Esu, E. O. (1994). Lineament Analysis for Groundwater exploration in Precambrian Oban Massif and Obudu Pateau, Southeastern, Nigeria. Journal of Mining and Geology, 30, 87-95.

Esu E. O. (1993). Fracture mapping-scientific basis for well sitting in hard rocks. Journal of Water Resources, 4, 25,35 .

Ezenabor B. O. (1985a). The Nature of Linear features and the limitations on the use of lineaments and fracture traces for groundwater Exploration in Nigeria. Journal of Mining and Geology, 22-31.

Ezenabor B. O. (1985b). Problems of remote detection of natural resources in Nigeria. Journal of Mining and Geology, 28, 52-64.

Habberjam G. M. (1975). Apparent Resistivity Anisotropy and Strike measurements. Geophys. Prospect, 23, 211-215. http://dx.doi.org/10.1111/j.1365-2478.1975.tb01525.x

Habberjam, G. M., \& Watkins, G. E. (1967). The use of a square configuration in resistivity prospecting. Geophysical Prospecting, 15, 221-235. http://dx.doi.org/10.1111/j.1365-2478.1967.tb01785.x

Hansen, B. P., \& Lane, J. W. (1996). Orientation And Characteristics Of Fractures In Crystalline Bedrock Determined By Surface And Borehole Geophysical Surveys, Millville and Uxbridge, Massachusetts: SAGEEP 1996 Conference, Environ. Eng. Geophys. Soc. Proceedings, 927-940.

Lane, J. W., Haeni, F. P., \& Watson, W. M. (1995). Use of a square-array direct-current resistivity method to detect fractures in crystalline bedrock in New Hampshire. Groundwater, 33, 476-485. http://dx.doi.org/10.1111/j.1745-6584.1995.tb00304.x

Loke M. H. (1999). Electrical Imaging surveys for environmental and engineering studies. A practical guide to 2-D and 3-D surveys. Terraplus Inf., 67p.

Malik, S. B., Bhattacharya, D. C., \& Nag, S. K. (1983). Behaviour of fractures in hard rocks - A study by surface geology and radial VES method. Geoexploration, 21, 181-189. http://dx.doi.org/10.1016/0016-7142(83)90063-7

Mamah, L. T., \& Ekine, A. S. (1989). Electrical resistivity anisotropy and Tectonism in basal Nsukka Formation. Journal of Mining and Geology, 25, 121-129.

Odeyemi, I. B., Malomo, S., \& Okufarasin, Y. A. (1985). Remote sensing of rock fractures and groundwater development success in parts of South-western Nigeria. Natural Resources Forum, 9, 311-315. http://dx.doi.org/10.1111/j.1477-8947.1985.tb01075.x 
Okurumeh, O. K., \& Olayinka, A. I. (1998). Electrical Anisotropy of crystalline Basement Rocks around Okeho, southwestern Nigeria: Implications in Geologic Mapping and Groundwater Investigation. Water resources. Journal of NAH, 9, 41-50.

Olayinka, A. I. (1996). Non Uniqueness in the Interpretation of Bedrock Resistivity from Sounding Curves and its Hydrological Implications. Water Resour. J. NAH, 7(1\&2), 55-60.

Olayinka, A. I. (1990). Electromagnetic profiling for groundwater in Precambrian Basement Complex Areas of Nigeria. Nordic Hydrology, pp. 205-216.

Olorunfemi, M. O., \& Opadokun, M. A. (1987). On the application of surface geophysical measurements in geological mapping-the basement complex of Southwestern Nigeria as a case study. Journal of African Earth Sciences, 6, 287-291. http://dx.doi.org/10.1016/0899-5362(87)90071-6

Olorunfemi, M. O, Ojo, J. S., \& Akintunde, O. M. (1999). Hydro-geophysical Evaluation of the groundwater protection of the Akure Metropolis, South Western Nigeria. Journal of Mining and Geology, 35(2), 201-228.

Rahaman, M. A. (1976). Review of the basement geology of Southwestern Nigeria. In: Kogbe, C.A. (Eds), Geology of Nigeria, 2nd ed. Elizabeth Publ., Lagos, pp. 36-56.

Skyernaa, L., \& Jorgensen, N. O. (1993). Detection of local fracture systems by azimuthal resistivity surveys: example from south Norway: Memoirs of the 24th congress of International Association of Hydrogeologists $662-671$.

Slater, L. D., Wishart, D. N., \& Gates, E. A. (2006). Self-potential improves characterization of hydraulically-active fracture from azimuthal geoelectrical measurements. Geophysical Res. Lett., 33, L17314.

Taylor, R. W., \& Fleming, A. H (1988). Characterizing jointed systems by azimthal resistivity surveys, Groundwater, 2, 464-474. http://dx.doi.org/10.1111/j.1745-6584.1988.tb00413.x

Zohdy, A. A. (1974). Application of Surface Geophysics to Groundwater Investigation. Techniques of water resources investigations of the US Geological Survey, Book2, pp. 5-66.

\section{Copyrights}

Copyright for this article is retained by the author(s), with first publication rights granted to the journal.

This is an open-access article distributed under the terms and conditions of the Creative Commons Attribution license (http://creativecommons.org/licenses/by/3.0/). 